\title{
Dynamic imaging for dynamic lung events
}

\author{
Tobias Becher $^{1} \mathbb{D} \cdot$ Dirk Schädler $^{1} \cdot$ Inéz Frerichs ${ }^{1}$
}

Received: 14 September 2021 / Accepted: 21 October 2021 / Published online: 29 October 2021

(c) The Author(s) 2021

Since the groundbreaking experimental studies on ventilatorinduced lung injury (VILI) performed in the 1990s [1], barotrauma, volutrauma and atelectrauma have been recognized as major causes of morbidity and mortality in mechanically ventilated patients with respiratory failure. In addition to the reduction in mortality provided by ventilation with lower tidal volumes [2], early restoration of spontaneous breathing has been shown to be beneficial in improving oxygen delivery and in shortening the duration of mechanical ventilation in patients with mildly impaired gas exchange [3]. Letting the patient breathe spontaneously through the ventilator may thus contribute to reducing the exposure time during which patients are mechanically ventilated and therefore at risk for developing VILI. The rationale for restoring early spontaneous breathing was further strengthened by demonstrating the long-term benefits of daily awakening and spontaneous breathing trials [4]. On the other hand, clinical research in patients with moderate-to-severe ARDS demonstrated that preventing spontaneous breathing through the use of neuromuscular blocking agents may reduce biotrauma [5] and lead to improved clinical outcomes [6]. These findings were supported by experimental studies demonstrating that high transpulmonary pressure swings associated with strong spontaneous breathing efforts may lead to worsening of lung injury [7] and produce local overstretch in inhomogeneously injured lungs [8]. The potentially injurious effects of vigorous spontaneous breathing in the presence of lung injury have since then been summarized under the still relatively new term "patient self-inflicted lung injury" (P-SILI) [9]. In patients with respiratory failure, the potential benefits of light sedation and spontaneous breathing must thus be balanced against the risks of P-SILI caused by excessive patient efforts, especially in the presence of inhomogeneous lung injury. This trade-off can also explain why a recent

Tobias Becher

tobias.becher@uksh.de

1 Klinik für Anästhesiologie und Operative Intensivmedizin, Universitätsklinikum Schleswig-Holstein, Campus Kiel, Kiel, Germany randomized controlled trial found no difference in outcome between a strategy of light sedation and spontaneous breathing, as compared to a strategy with deep sedation and neuromuscular blockade in patients with ARDS [10]. The possible benefits of neuromuscular blocking agents in preventing P-SILI may, on average, have been offset by the harm caused by the necessary deeper sedation levels. The clinical challenge is therefore to find a method for identifying individual patients who are at increased risk for developing P-SILI, as in these patients, the potential benefits provided by a strategy of deep sedation and muscle relaxation may outweigh the adverse effects this strategy inevitably entails.

In this issue of the Journal of Clinical Monitoring and Computing, Pulletz and coworkers present an innovative approach for determining the dynamic regional relative strain (DRRS) with electrical impedance tomography (EIT) during unassisted spontaneous breathing [11]. DRRS is obtained by calculating the ratio between normalized pixel values of tidal impedance change and end-expiratory lung impedance (EELI). This method has the potential of identifying regional overdistension during unassisted spontaneous breathing: higher values of DRRS indicate lung areas with a high ratio between tidal volume and end-expiratory lung volume (strain). As high inspiratory strain is a known risk factor for development of volutrauma [12], high values of DRRS could identify lung areas at risk for volutrauma, even during unassisted spontaneous breathing.

In their present study, Pulletz and coworkers compared DRRS between a group of spontaneously breathing patients suffering from COVID-19 and a control group of healthy volunteers. They found that elevated pixel values of DRRS were more frequent in COVID-19 patients as compared to healthy controls. As COVID-19 patients may be at increased risk for developing P-SILI [13], these data indicate that DRRS could prove to be a useful marker for early recognition of potentially injurious spontaneous efforts.

The potential of the new method, however, comes with a few caveats: As a consequence of the normalization procedure, the average DRRS value of the patient's lungs is always close to 1 , regardless of the severity of lung damage 
or the vigorousness of spontaneous efforts. DRRS therefore only provides regional information on lung areas that are more distended in comparison to the rest of this individual patient's lungs. If, as a consequence of inhomogeneous lung damage, some lung regions exhibit an above-average stretch, DRRS for these lung regions will assume higher values, indicating relative regional overdistension. If, on the other hand, lung stretch is distributed homogeneously across the whole lung without any particularly overdistended areas, DRRS may remain close to 1 even if the entire lung is already dangerously close to overdistension. Moreover, as the calculation of DRRS is based on a comparison between normalized pixel values of tidal impedance change and EELI, it may be influenced by the application of PEEP. High levels of PEEP may thus lead to potentially lower values of DRRS in lung regions that are already overdistended at end-expiration and whose tidal impedance change is therefore low in comparison to their already-high EELI.

Despite these caveats, Pulletz and coworkers present an intriguing approach that adresses a previously unresolved clinical challenge: identifying patients at risk for P-SILI while they are still breathing spontaneously without assistance.

Funding Open Access funding enabled and organized by Projekt DEAL. No funding was received for this commentary.

\section{Data availability Not applicable.}

\section{Declarations}

Conflict of interest TB has received lecture fees from Drägerwerk AG \& Co. KGaA, Sedana Medical and Löwenstein Medical. DS has received lecture fees from Aerogen Ltd. IF has received funding from the European Commission (Projects CRADL, under Grant 668259, and WELMO, under Grant 825572) and speaking and congress fees from Drägerwerk AG \& Co. KGaA.

Open Access This article is licensed under a Creative Commons Attribution 4.0 International License, which permits use, sharing, adaptation, distribution and reproduction in any medium or format, as long as you give appropriate credit to the original author(s) and the source, provide a link to the Creative Commons licence, and indicate if changes were made. The images or other third party material in this article are included in the article's Creative Commons licence, unless indicated otherwise in a credit line to the material. If material is not included in the article's Creative Commons licence and your intended use is not permitted by statutory regulation or exceeds the permitted use, you will need to obtain permission directly from the copyright holder. To view a copy of this licence, visit http://creativecommons.org/licenses/by/4.0/.

\section{References}

1. Dreyfuss D, Saumon G. Ventilator-induced lung injury: lessons from experimental studies. Am J Respir Crit Care Med.
1998;157(1):294-323. https://doi.org/10.1164/ajrccm.157.1.96040 14.

2. Acute Respiratory Distress Syndrome Network, Brower RG, Matthay MA, Morris A, Schoenfeld D, Thompson BT, Wheeler A. Ventilation with lower tidal volumes as compared with traditional tidal volumes for acute lung injury and the acute respiratory distress syndrome. N Engl J Med. 2000;342(18):1301-8. https://doi.org/10. 1056/NEJM200005043421801.

3. Putensen C, Zech S, Wrigge H, Zinserling J, Stüber F, Von Spiegel T, Mutz N. Long-term effects of spontaneous breathing during ventilatory support in patients with acute lung injury. Am J Respir Crit Care Med. 2001;164(1):43-9. https://doi.org/10.1164/ajrccm.164.1. 2001078

4. Girard TD, Kress JP, Fuchs BD, Thomason JW, Schweickert WD, Pun BT, Taichman DB, Dunn JG, Pohlman AS, Kinniry PA, Jackson JC, Canonico AE, Light RW, Shintani AK, Thompson JL, Gordon SM, Hall JB, Dittus RS, Bernard GR, Ely EW. Efficacy and safety of a paired sedation and ventilator weaning protocol for mechanically ventilated patients in intensive care (Awakening and Breathing Controlled trial): a randomised controlled trial. Lancet. 2008;371(9607):126-34. https://doi.org/10.1016/S0140-6736(08) 60105-1.

5. Forel JM, Roch A, Marin V, Michelet P, Demory D, Blache JL, Perrin G, Gainnier M, Bongrand P, Papazian L. Neuromuscular blocking agents decrease inflammatory response in patients presenting with acute respiratory distress syndrome. Crit Care Med. 2006;34(11):2749-57. https://doi.org/10.1097/01.CCM.00002 39435.87433.0D.

6. Papazian L, Forel JM, Gacouin A, Penot-Ragon C, Perrin G, Loundou A, Jaber S, Arnal JM, Perez D, Seghboyan JM, Constantin JM, Courant P, Lefrant JY, Guérin C, Prat G, Morange S, Roch A, ACURASYS Study Investigators. Neuromuscular blockers in early acute respiratory distress syndrome. N Engl J Med. 2010;363(12):110716. https://doi.org/10.1056/NEJMoa1005372.

7. Yoshida T, Uchiyama A, Matsuura N, Mashimo T, Fujino Y. Spontaneous breathing during lung-protective ventilation in an experimental acute lung injury model: high transpulmonary pressure associated with strong spontaneous breathing effort may worsen lung injury. Crit Care Med. 2012;40(5):1578-85. https://doi.org/10.1097/CCM. 0b013e3182451c40.

8. Yoshida T, Torsani V, Gomes S, De Santis RR, Beraldo MA, Costa EL, Tucci MR, Zin WA, Kavanagh BP, Amato MB. Spontaneous effort causes occult pendelluft during mechanical ventilation. Am J Respir Crit Care Med. 2013;188(12):1420-7. https://doi.org/10. 1164/rccm.201303-0539OC.

9. Brochard L, Slutsky A, Pesenti A. Mechanical ventilation to minimize progression of lung injury in acute respiratory failure. Am J Respir Crit Care Med. 2017;195(4):438-42. https://doi.org/10.1164/ rccm.201605-1081CP.

10. National Heart, Lung, and Blood Institute PETAL Clinical Trials Network, Moss M, Huang DT, Brower RG, Ferguson ND, Ginde AA, Gong MN, Grissom CK, Gundel S, Hayden D, Hite RD, Hou PC, Hough CL, Iwashyna TJ, Khan A, Liu KD, Talmor D, Thompson BT, Ulysse CA, Yealy DM, Angus DC. Early neuromuscular blockade in the acute respiratory distress syndrome. N Engl J Med. 2019;380(21):1997-2008. https://doi.org/10.1056/NEJMoa1901 686.

11. Pulletz S, Krukewitt L, Gonzales-Rios P, Teschendorf P, Kremeier P, Waldmann A, Zitzmann A, Müller-Graf F, Acosta C, Tusman G, Reuter DA, Böhm SH. Dynamic relative regional strain visualized by electrical impedance tomography in patients suffering from COVID-19. J Clin Monit Comput. 2021;13:1-11. https://doi.org/10. 1007/s10877-021-00748-3.

12. Protti A, Cressoni M, Santini A, Langer T, Mietto C, Febres D, Chierichetti M, Coppola S, Conte G, Gatti S, Leopardi O, Masson S, Lombardi L, Lazzerini M, Rampoldi E, Cadringher P, Gattinoni 
L. Lung stress and strain during mechanical ventilation: any safe threshold? Am J Respir Crit Care Med. 2011;183(10):1354-62. https://doi.org/10.1164/rccm.201010-1757OC (Erratum in: Am J RespirCrit Care Med. 2012 Jan 1;185(1):115).

13. Weaver L, Das A, Saffaran S, Yehya N, Scott TE, Chikhani M, Laffey JG, Hardman JG, Camporota L, Bates DG. High risk of patient self-inflicted lung injury in COVID-19 with frequently encountered spontaneous breathing patterns: a computational modelling study. Ann Intensive Care. 2021;11(1):109. https://doi.org/10.1186/ s13613-021-00904-7.

Publisher's Note Springer Nature remains neutral with regard to jurisdictional claims in published maps and institutional affiliations. 